\title{
Prognostic significance of pretreatment albumin/ globulin ratio in patients with hepatocellular carcinoma
}

This article was published in the following Dove Press journal:

OncoTargets and Therapy

24 August 2016

Number of times this article has been viewed

\author{
Yan Deng \\ Qing Pang \\ Run-Chen Miao \\ Wei Chen \\ Yan-Yan Zhou \\ Jian-Bin Bi \\ Su-Shun Liu \\ Jing-Yao Zhang \\ Kai Qu \\ Chang Liu
}

Department of Hepatobiliary Surgery, The First Affiliated Hospital of Medical College, Xi'an Jiaotong University, Xi'an, Shaanxi Province, People's Republic of China
Correspondence: Chang Liu

Department of Hepatobiliary Surgery, The First Affiliated Hospital of Medica College, Xi'an Jiaotong University, No 277 West Yan-ta Road, Xi'an 71006I, Shaanxi Province, People's Republic of China

Tel +86298265 3900

Fax +86 2982653905

Email liuchangdoctor@I63.com
Background: Pretreatment nutritional and immunological statuses play an indispensable role in predicting the outcome of patients with various types of malignancies. The purpose of this study is to evaluate the predictive value of albumin/globulin ratio (AGR) in overall survival (OS) and recurrence in patients with hepatocellular carcinoma (HCC) following radical hepatic carcinectomy.

Patients and methods: This retrospective study included a total of 172 patients with HCC with complete medical and follow-up information between 2002 and 2012. AGR was calculated according to the following formula: AGR = albumin/globulin. Receiver operating characteristic curve analysis was performed to determine the optimal cutoff value. The associations of AGR with clinicopathological characteristics and prognosis were assessed. Further multivariate analysis using Cox regression model and subgroup analysis was performed to evaluate the predictive value.

Results: Receiver operating characteristic curve determined 37.65, 31.99, and 1.48 as the optimal cutoff values of albumin, globulin, and AGR in terms of 5-year OS or death, respectively. On the basis of the cutoff value of AGR, all the patients were divided, respectively, into low-AGR ( $\mathrm{n}=105)$ and high-AGR ( $\mathrm{n}=67)$ groups. AGR was found to be significantly correlated with age, cancer embolus, international normalized ratio, and postoperative outcome $(P<0.05)$. Hepatitis B virus infection (hazard ratio [HR]: 2.125; 95\% confidence interval [CI]: 1.285-3.153), tumor node metastasis stage (HR: 1.656; 95\% CI: 1.234-2.223), serum albumin (HR: 0.546; 95\% CI: 0.347-0.857), and AGR (HR: 0.402; 95\% CI: 0.233-0.691) were independent predictors of OS via univariate and multivariate survival analyses. However, alpha-fetoprotein (HR 1.708; 95\% CI: 1.027-2.838), tumor node metastasis stage (HR: 1.464; 95\% CI: 1.078-1.989), and AGR (HR: 0.493; 95\% CI: 0.293-0.828) functioned as independent risk variables for predicting recurrence. Moreover, AGR showed superior prognostic value for OS and recurrence in the subgroups with normal level of albumin or survival time beyond 6 months.

Conclusion: Pretreatment AGR might serve as an effective biomarker to evaluate the prognosis of patients with a diagnosis of HCC. Based on the results, AGR, characterized with easy accessibility, objectivity, and noninvasiveness, should be included in the routine assessment of HCC.

Keywords: hepatocellular carcinoma, albumin/globulin ratio, prognosis, survival, recurrence

\section{Introduction}

Hepatocellular carcinoma (HCC) is one of the most prevalent malignancies, with increasing incidence and mortality worldwide. ${ }^{1,2}$ Curative resection, which might significantly ameliorate the prognosis of patients with $\mathrm{HCC}$, is a potentially effective 
treatment strategy. However, the majority of persons have lost the chance of accepting curative surgery due to the clinical characteristics of HCC, including easy local invasion, lymph node, vascular, distant metastasis, and no symptom in the early days..$^{2-4}$ Despite improved diagnostic and treatment strategy, the prognosis of patients with HCC suffering from hepatic carcinectomy remains poor, which indicated that those patients had not benefited from the operation. ${ }^{5}$ Hence, there is a need to further delineate prognostic determinants of predicting the risk of mortality and recurrence in order to better stratify those patients likely to benefit from surgical treatment and to assist with clinical decision-making in case of unnecessary toxicity and morbidity.

Of note, mounting evidence suggests that the presence of the systemic inflammatory response, reflected in routine hematology, has a decidedly protumor capacity leading to poor prognosis in a host of malignant neoplasms. ${ }^{6-9}$ Albumin and globulin, the major constituents of serum proteins, have a vital effect on the systemic inflammatory response. Previous examinations had demonstrated that low serum albumin, a marker of nutrition state and chronic inflammation, is an independent predictor of mortality and recurrence rate in several types of malignancies. ${ }^{10}$ Furthermore, globulin is of significant importance not only for host immunity and inflammation but also as a reaction for cumulative exposure of different cytokines. Studies even deemed that globulin might be an independent risk factor for predicting long-term mortality in colorectal or gastric cancer. ${ }^{11,12}$ Pretreatment nutritional and immunological statuses play an equally indispensable role in predicting the outcome of patients with various types of malignancies. However, few reports have looked into the effect of albumin/globulin ratio (AGR) on patients with HCC suffering from hepatic carcinectomy. Hence, we conducted a retrospective analysis to investigate the relationship between preoperative AGR and clinicopathological features as well as outcome in patients with HCC.

\section{Patients and methods Study population}

A cohort of 172 patients with a diagnosis of HCC presented to the First Affiliated Hospital of the Xi'an Jiaotong University College of Medicine between 2002 and 2012 were included in this retrospective study. All the patients underwent primary radical hepatic carcinectomy, and tissue specimens were pathologically proven to be HCC. Complete medical and follow-up information was obtained from records or telephone interviews. Patients with the following conditions were excluded: 1) multiple cancers; 2) incomplete laboratory test information such as serum albumin or globulin; 3) concomitant diseases that affect the level of serum albumin or globulin such as lymphoblastic leukemia and autoimmune disease; and 4) rehepatectomy. Our study was approved by the ethical committee of the First Affiliated Hospital of the Xi'an Jiaotong University College of Medicine. Written informed patient consent was obtained. Patient records/information were anonymized and deidentified prior to analysis.

\section{Data collection}

Clinicopathological variables, including demographic data (age, sex, smoking, and drinking), blood picture, hepatitis B, hepatitis $\mathrm{C}$, serum albumin, globulins, alpha-fetoprotein (AFP), Child-Turcotte-Pugh (CTP) class, tumor node metastasis (TNM) stage, and pathological reports, were collected. Clinical, radiological criteria (computed tomography scan), and histological evidence were used to diagnose the presence of liver cirrhosis in all patients. Preoperative data were obtained before surgery, and the blood samples were collected from the first day of patients' admission. The earliest set of measurements was used if there were more than one set for a same patient. AGR was calculated using the equation: $\mathrm{AGR}=$ albumin/total protein - albumin. The TNM staging system for HCC is based on the American Joint Committee on Cancer (seventh edition). ${ }^{13}$

\section{Follow-up}

All the patients received follow-up routinely until November 2013. Overall survival (OS) was computed from the time of surgery to our unit. The time to recurrence was defined as the interval between surgery and recurrence or the last observation without recurrence. All the cohort patients were followed up every 3 months for the first year, every 4 months for the second year, and every 6 months thereafter. The content embraces AFP, ultrasonic, and abdominal computed tomography. When postoperative serum AFP value of patients is $>20 \mathrm{ng} / \mathrm{mL}$ or ultrasonic/abdominal computed tomography finds new focus, we harbored the idea that they had suffered from tumor recurrence in the work. During the follow-up period, the relevant information, including death and recurrence time, AFP, and imaging result, was recorded in detail. For the sake of reducing the bias to maximum extent, there were two clinicians to complete the follow-up and review, respectively.

\section{Statistical analysis}

For continuous variables, the data were expressed as the mean value \pm standard deviation or median (minimummaximum) based on whether they meet the distributed Kolmogorov-Smirnov test, $(P<0.05)$ or not. Categorical 
data were presented as frequency. Hence, the significance of difference between two groups was determined using the Student's $t$-test or Wilcoxon test for continuous variables and the Chi-squared test for categorical datum. The receiver operating characteristic (ROC) curve with 5-year OS was used to determine the ideal cutoff point, which allows the prediction for 5 -year OS with the best sensitivity and specificity. Based on the cutoff point, patients were divided into two groups, namely the high-AGR group and the low-AGR group.

Survival curves for patients were estimated using the Kaplan-Meier method, and the difference among the curves was analyzed using the log-rank test. Factors showing significant prognostic value in the univariate analysis were further analyzed in the final multivariate Cox proportional hazards model. All statistical analyses were performed using PASW Statistics 22.0 software (IBM Corporation, Armonk, NY, USA). Finally, subgroup analysis was used to exclude confounding factors. Two-sided $P$-values of $<0.05$ were considered statistically significant.

\section{Results}

\section{Patient characteristics}

The baseline clinicopathological characteristics of 172 patients with a diagnosis of HCC, including 139 males and 33 females
( $80.81 \%$ vs $19.19 \%)$, are summarized in Table 1 . The median age of the patients was 53 years (range 24-80). The liver function of most patients was compensatory (Child A, 92.44\%). Moreover, the majority of patients suffered from hepatitis B virus (HBV) infection (121/172, 70.35\%), and they were classified, respectively, as TNM I (92/172, $53.49 \%)$, TNM II $(42 / 172,24.42 \%)$, or TNM III (38/172, $22.09 \%$ ) according to TNM staging system. No TNM IV patients were included in the study because those patients had lost the chance of receiving operation based on Milan criteria. A minority of patients had a history of drinking, smoking, and hepatitis $\mathrm{C}$ virus infection and had been diagnosed with cirrhosis $(34.30 \%)$. In addition, postoperative pathology confirmed that 15 patients with cancer embolus were included.

Among the 172 selected patients who were examined during the follow-up period, 81 patients $(47.29 \%)$ died and 75 patients $(43.60 \%)$ were diagnosed with tumor recurrence. Median time of OS and recurrence was 31 months (range 1-120) and 20 months (range 1-117), respectively.

\section{ROC curve analysis}

ROC curve analysis was performed to determine the optimal cutoff values of AGR and albumin in terms of 5-year OS and

Table I Associations between clinicopathological features and AGR

\begin{tabular}{|c|c|c|c|c|}
\hline Parameters & Overall $(n=\mid 72)$ & $\begin{array}{l}\text { High-AGR group } \\
(A G R \geq 1.48)(n=67)\end{array}$ & $\begin{array}{l}\text { Low-AGR group } \\
(A G R<1.48)(n=105)\end{array}$ & $P$-value \\
\hline Age (years) & $53(24-80)$ & $52(24-80)$ & $54(28-75)$ & $0.002^{\mathrm{a}}$ \\
\hline Sex (male/female) & $139 / 33$ & $58 / 9$ & $81 / 24$ & $0.126^{\mathrm{b}}$ \\
\hline Smoking (yes/no) & $68 / 104$ & $28 / 39$ & $40 / 65$ & $0.629^{\mathrm{b}}$ \\
\hline Drinking (yes/no) & $40 / 132$ & $|6 / 5|$ & $24 / 81$ & $0.877^{\mathrm{b}}$ \\
\hline $\operatorname{AFP}(\mathrm{ng} / \mathrm{mL})$ & $95.67(1.31-69,677.00)$ & $43.39(1.31-69,677.00)$ & $240.90(1.87-65,898.00)$ & $0.890^{\mathrm{a}}$ \\
\hline INR & I.06 (0.73-I.63) & $1.03(0.76-1.63)$ & $1.09(0.73-1.62)$ & $0.002^{\mathrm{a}}$ \\
\hline Platelet $(<100 / \geq 100)\left(10^{9} / \mathrm{L}\right)$ & $58 / 114$ & $22 / 45$ & $36 / 69$ & $0.845^{\mathrm{b}}$ \\
\hline CTP Class (A/B) & $159 / 13$ & $65 / 2$ & $94 / 11$ & $0.070^{\mathrm{b}}$ \\
\hline HBV infection (yes/no) & $|2| / 5 \mid$ & $50 / 17$ & $71 / 34$ & $0.326^{\mathrm{b}}$ \\
\hline HCV infection (yes/no) & $8 / 164$ & $1 / 66$ & $7 / 98$ & $0.138^{b}$ \\
\hline Cancer embolus (yes/no) & $15 / 157$ & $1 / 66$ & $|4 / 9|$ & $0.007^{b}$ \\
\hline Tumor number $(I />I)$ & $140 / 32$ & $57 / 10$ & $83 / 22$ & $0.322^{b}$ \\
\hline Tumor size $(<5 / \geq 5)(\mathrm{cm})$ & $58 / 114$ & $28 / 39$ & $30 / 75$ & $0.074^{\mathrm{b}}$ \\
\hline Vascular invasion (yes/no) & $12 / 160$ & $2 / 65$ & $10 / 95$ & $0.101^{\mathrm{b}}$ \\
\hline TNM I/II/III & $92 / 42 / 38$ & $42 / 16 / 9$ & $50 / 26 / 29$ & $0.065^{\mathrm{b}}$ \\
\hline $\mathrm{BCLC}$ stage $\mathrm{AI}+\mathrm{A} 2 / \mathrm{A} 3+\mathrm{A} 4 / \mathrm{B} / \mathrm{C}+\mathrm{D}$ & $58 / 15 / 79 / 20$ & $27 / 9 / 25 / 6$ & $31 / 6 / 54 / 14$ & $0.084^{b}$ \\
\hline Liver cirrhosis (yes/no) & $59 / 113$ & $18 / 49$ & $4 I / 64$ & $0.10 I^{b}$ \\
\hline Serum albumin $(g / L)$ & $38.2 I \pm 0.4 I$ & $42.27 \pm 4.98$ & $37.07 \pm 4.97$ & $<0.00 \mathrm{I}^{\mathrm{c}}$ \\
\hline Globulin & $29.55(15.56-50.20)$ & $24.80(15.56-32.00)$ & $32.30(21.30-50.20)$ & $<\mathbf{0 . 0 0}^{\mathrm{a}}$ \\
\hline Lymphocytes $\left(10^{9} / \mathrm{L}\right)$ & $1.36(0.27-4.73)$ & $1.34(0.27-3.21)$ & $1.32(0.30-4.73)$ & $0.713^{\mathrm{a}}$ \\
\hline Survival time (minutes) & $31(1-120)$ & $39(2-120)$ & $25(1-117)$ & $<\mathbf{0 . 0 0}^{\mathrm{a}}$ \\
\hline Death (yes/no) & $81 / 91$ & $18 / 49$ & $63 / 42$ & $<0.00 \mathrm{I}^{\mathrm{b}}$ \\
\hline Recurrence time (minutes) & $20(1-117)$ & $38(2-115)$ & $13(1-117)$ & $<0.00 \mathrm{I}^{\mathrm{a}}$ \\
\hline Relapse (yes/no) & $75 / 97$ & $21 / 46$ & $54 / 51$ & $0.010^{b}$ \\
\hline
\end{tabular}

Notes: aWilcoxon test; ${ }^{b} \chi^{2}$ test; and 'Student's $t$-test. The values are expressed as the median (range), mean \pm standard deviation, or number. Bold font represents $P<0.05$ and the relevant variables are statistically significant.

Abbreviations: AGR, albumin/globulin ratio; AFP, alpha-fetoprotein; INR, International Normalized Ratio; HBV, hepatitis B virus; HCV, hepatitis C virus; TNM, tumor node metastasis; BCLC, Barcelona clinical liver cancer; CTP, Child-Turcotte-Pugh. 
globulin with 5-year death. When the Youden index was the maximum, the optimal cutoff point was obtained. As shown in Figure 1, the optimal cutoff values of albumin, globulin, and AGR were 37.65 (sensitivity of $71.4 \%$ and specificity of $49.4 \%$, area under the curve $(\mathrm{AUC})=0.627,95 \% \mathrm{CI}$ $0.570-0.735, P=0.004$ ), 31.98 (sensitivity of $44.4 \%$ and specificity of $75.8 \%$, AUC $=0.596,95 \%$ CI: $0.511-0.681$, $P=0.030$ ), and 1.48 (sensitivity of $53.8 \%$ and specificity of $77.8 \%$, AUC $=0.652$, 95\% CI $0.544-0.711, P<0.001$ ), respectively. On the basis of the cutoff value of AGR, the whole cohort was divided into high-AGR group $(n=67)$ and low-AGR group $(\mathrm{n}=105)$.

\section{Associations between AGR and clinicopathological features}

The associations between AGR and various clinicopathological factors are shown in Table 1. Interestingly, compared with patients in the high-AGR group, participants in the low-AGR group were significantly associated with cancer embolus and high international normalized ratio. Additionally, it was not arduous to find that elderly patients were prone to appear in the low-AGR group. No significant distribution difference was found in sex, smoking, drinking, HBV and hepatitis $\mathrm{C}$ virus infections, CTP classification, low platelet, TNM stage, Barcelona clinical liver cancer (BCLC) stage, and level of AFP as well as the presence of liver cirrhosis between two groups.

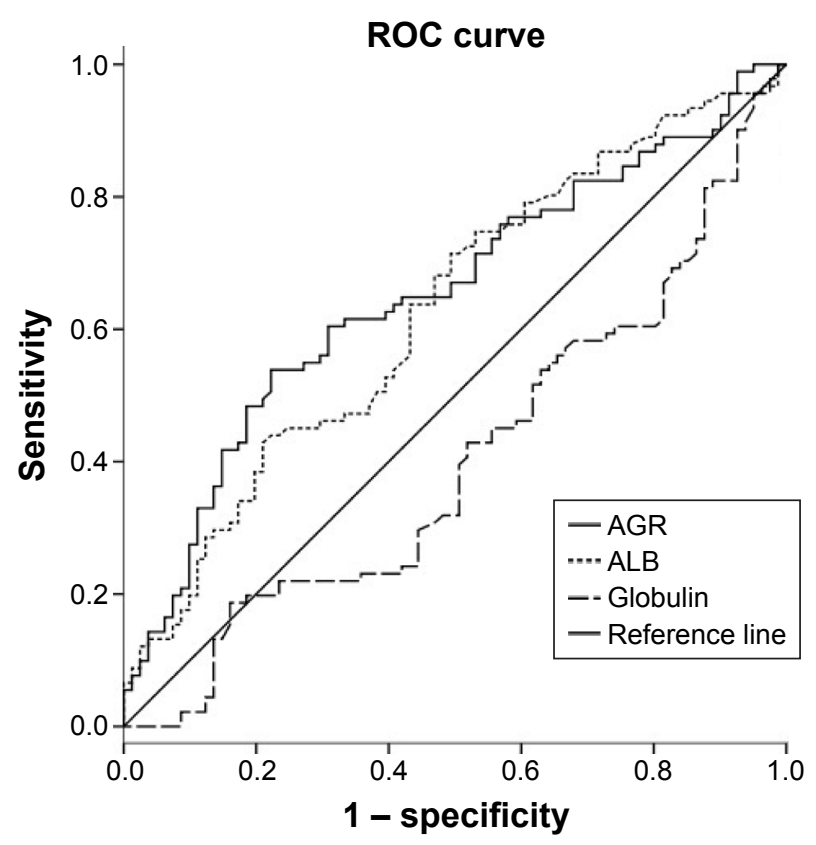

Figure I ROC analysis for optimal cutoff values of ALB, GLB, and AGR.

Note: The optimal cutoff values of ALB, GLB, and AGR were 37.65, 31.99, and I.48, respectively.

Abbreviations: ROC, receiver operating characteristic; ALB, albumin; GLB, globulin; AGR, albumin/globulin ratio.

\section{Predictors of OS and recurrence}

At the end of follow-up, $81(47.09 \%)$ patients died and $75(43.60 \%)$ patients experienced tumor recurrence, including local recurrence and distance metastasis. In the cohort, the 1-, 2-, and 5-year OS rates of postoperative patients were 76.7\%, $64.9 \%$, and $48.4 \%$, respectively. The relationship between AGR and outcome is presented in Table 2. Low AGR value was associated with reduced OS and high recurrence rates. The 1-, 2-, and 5-year OS rates were 89.6\%, 81.9\%, and $71.9 \%$ in the high-AGR group and $68.6 \%, 54.1 \%$, and $46.0 \%$ in the low-AGR group, respectively. Besides, patients in the high-AGR group had lower 1-year (15.5\% vs 39.4\%), 2-year (29.9\% vs $55.2 \%)$, and 5-year (60.6\% vs $65.6 \%)$ recurrence rates compared with those in the low-AGR group.

Using univariate analysis, AGR $(P<0.001)$, AFP $\geq 400 \mathrm{ng} / \mathrm{mL}(P=0.049)$, albumin $(P=0.002)$, globulin $(P=0.020), \mathrm{HBV}$ infection $(P=0.048)$, presence of cancer embolus $(P=0.023)$, and TNM stage $(P<0.001)$ were found to be significant predictors of cancer-specific OS. Kaplan-Meier survival analysis revealed that patients in the low-AGR group had worse OS than those in the highAGR group (Figure 2A). Furthermore, multivariate analysis identified TNM stage (hazard ratio [HR]: 1.656; 95\% CI: 1.234-2.223; $P=0.001$ ), HBV infection (HR: $2.125 ; 95 \%$ CI: $1.285-3.513 ; P=0.003$ ), serum albumin (HR: 0.546 ; 95\% CI: 0.347-0.857; $P=0.009$ ), and AGR (HR: 0.402; 95\% CI: $0.233-0.691 ; P=0.001)$ as independent risk predictors of postoperative OS (Table 3 ).

In our study, higher risk of recurrence via individual Cox regression was noted in patients with albumin $(P=0.033)$, globulin $(P=0.020)$, AFP $(P=0.005)$, presence of cancer embolus $(P=0.024)$, and TNM stage $(P=0.001)$ as well as $\operatorname{AGR}(P=0.001)$. As shown in Figure $2 \mathrm{~B}$, a lower AGR value was associated with shorter time to recurrence $(P=0.001)$. We further screened out independent risk variables including AFP (HR: 1.708; 95\% CI: 1.027-2.838; $P=0.039$ ), TNM stage (HR: $1.464 ; 95 \% \mathrm{CI}: 1.078-1.989 ; P=0.0015)$, and AGR (HR: 0.493 ; 95\% CI: $0.293-0.828 ; P=0.008$ ) in Cox proportional hazard multivariate models (Table 4 ).

\section{Additional analyses}

The TNM stage was considered to be a potent predictor of $\mathrm{OS}$ and recurrence for $\mathrm{HCC}$, which was confirmed by our study (Figure 3A and B). All the patients were stratified according to the TNM staging system. Kaplan-Meier curves of patients with different TNM stages in terms of OS and recurrence are shown in Figure $4 \mathrm{~A}-\mathrm{F}$. The difference was unfolded between two groups in Kaplan-Meier plots. In addition, a statistically significant difference in OS was confirmed 
Table 2 The overall survival and recurrence rate of patients between high and low groups based on cutoff point of albumin, globulin, and $A G R$, respectively

\begin{tabular}{|c|c|c|c|c|c|c|c|c|c|c|c|}
\hline \multirow[t]{2}{*}{ Rate } & \multirow[t]{2}{*}{ Time } & \multirow{2}{*}{$\begin{array}{l}\text { Total } \\
(n=\mid 72)\end{array}$} & \multicolumn{3}{|c|}{ Albumin } & \multicolumn{3}{|c|}{ Globulin } & \multicolumn{3}{|l|}{ AGR } \\
\hline & & & $\begin{array}{l}\text { Low } \\
\text { group } \\
(n=66)\end{array}$ & $\begin{array}{l}\text { High } \\
\text { group } \\
(n=106)\end{array}$ & $P$-value & $\begin{array}{l}\text { Low } \\
\text { group } \\
(n=56)\end{array}$ & $\begin{array}{l}\text { High } \\
\text { group } \\
(n=|| 6)\end{array}$ & $P$-value & $\begin{array}{l}\text { Low } \\
\text { group } \\
(n=105)\end{array}$ & $\begin{array}{l}\text { High } \\
\text { group } \\
(n=67)\end{array}$ & $P$-value \\
\hline \multirow[t]{3}{*}{ Overall survival (\%) } & I year & 76.7 & 70.1 & 81.0 & 0.084 & 79.3 & 71.4 & 0.326 & 68.6 & 89.6 & 0.001 \\
\hline & 2 years & 64.9 & 54.8 & 71.3 & 0.022 & 69.5 & 55.4 & 0.070 & 54.1 & 81.9 & $<0.001$ \\
\hline & 5 years & 48.4 & 32.4 & 63.0 & $<0.001$ & 61.1 & 31.3 & $<\mathbf{0 . 0 0 I}$ & 46.0 & 71.9 & 0.001 \\
\hline \multirow[t]{3}{*}{ Recurrence (\%) } & I year & 29.5 & 34.2 & 26.6 & 0.239 & 23.7 & 41.5 & 0.020 & 39.4 & 15.5 & $<0.001$ \\
\hline & 2 years & 44.7 & 55.9 & 38.1 & 0.026 & 39.4 & 55.6 & 0.051 & 55.2 & 29.9 & 0.457 \\
\hline & 5 years & 49.9 & 60.3 & 43.8 & 0.028 & 43.7 & 62.4 & 0.017 & 65.6 & 60.6 & 0.532 \\
\hline
\end{tabular}

Notes: The $P$-values were calculated by Chi-squared test. Bold font represents $P<0.05$ and the relevant variables are statistically significant. Abbreviation: AGR, albumin/globulin ratio.
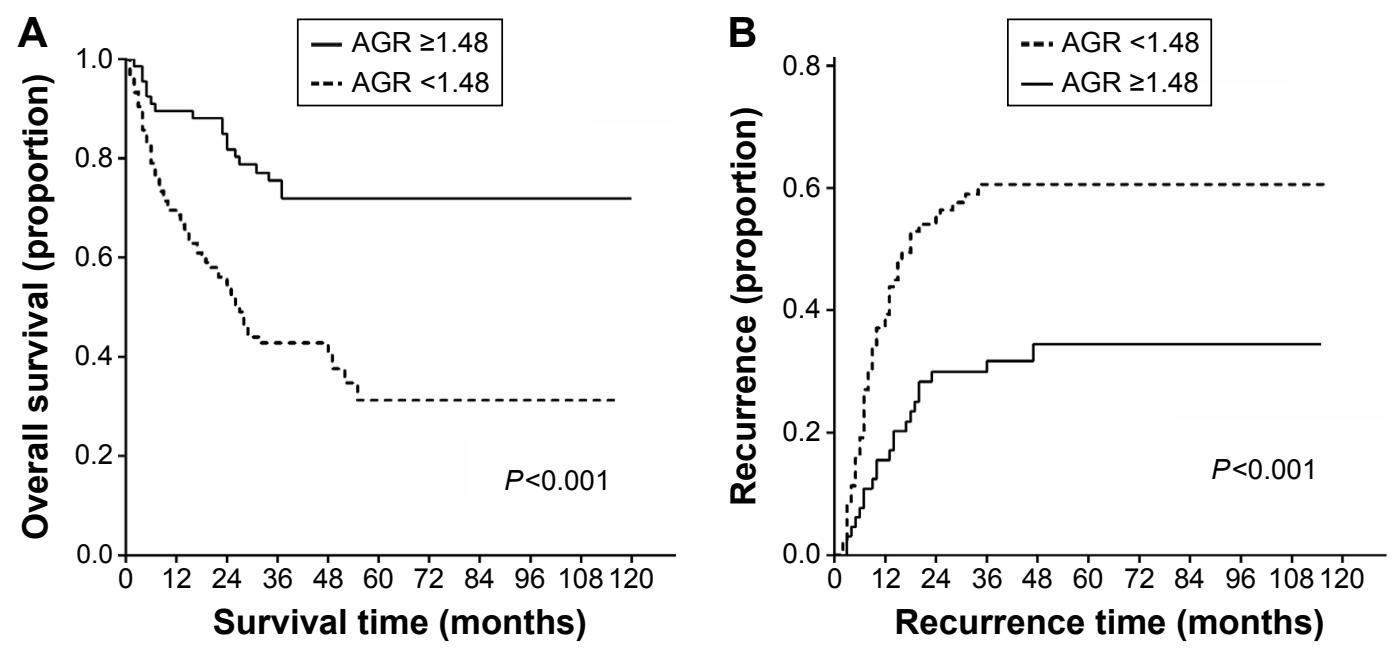

Figure 2 Kaplan-Meier curves for (A) OS and (B) recurrence between high-AGR (AGR $\geq 1.48$ ) and low-AGR (AGR $<$ I.48).

Note: The $P$-values were calculated by log-rank test.

Abbreviations: OS, overall survival; AGR, albumin/globulin ratio.

Table 3 Univariate and multivariate analysis of factors associated with HCC overall survival

\begin{tabular}{|c|c|c|c|c|}
\hline \multirow[t]{2}{*}{ Parameters } & \multicolumn{2}{|c|}{ Univariate analysis } & \multicolumn{2}{|c|}{ Multivariate analysis } \\
\hline & $P$-value & HR (95\% Cl) & $P$-value & HR (95\% Cl) \\
\hline Age $>60$ years & 0.053 & $1.556(0.993-2.437)$ & & \\
\hline Sex (male/female) & 0.849 & $1.055(0.610-1.824)$ & & \\
\hline Smoking (yes/no) & 0.376 & $0.812(0.51 \mathrm{I}-1.289)$ & & \\
\hline Drinking (yes/no) & 0.054 & $0.547(0.296-1.010)$ & & \\
\hline AFP $\geq 400 \mathrm{ng} / \mathrm{mL}$ & 0.049 & $1.600(1.003-2.552)$ & 0.087 & $1.534(0.940-2.503)$ \\
\hline Platelet $<100\left(10^{9} / \mathrm{L}\right)$ & 0.367 & $0.804(0.50 \mathrm{I}-1.290)$ & & \\
\hline CTP Class (A/B) & 0.191 & I.68I (0.772-3.660) & & \\
\hline HBV infection (yes/no) & 0.048 & $1.583(1.003-2.498)$ & 0.003 & $2.125(1.285-3.513)$ \\
\hline $\mathrm{HCV}$ infection (yes/no) & 0.728 & $0.815(0.257-2.583)$ & & \\
\hline Cancer embolus (yes/no) & 0.023 & $2.100(1.110-3.97 \mid)$ & 0.733 & I.I34 (0.550-2.340) \\
\hline Tumor size $(<5 / \geq 5)(\mathrm{cm})$ & $<0.00$ I & $5.114(2.633-9.931)$ & & \\
\hline Tumor number $(I />I)$ & 0.151 & $\mathrm{I} .448(0.874-2.40 \mathrm{I})$ & & \\
\hline TNM stage (per increase I stage) & $<\mathbf{0 . 0 0 I}$ & $1.658(I .28 I-2.416)$ & 0.001 & $1.656(1.234-2.223)$ \\
\hline BCLC stage (per increase I stage) & $<\mathbf{0 . 0 0 1}$ & $1.744(1.343-2.344)$ & & \\
\hline Liver cirrhosis (yes/no) & 0.490 & $0.847(0.528-1.357)$ & & \\
\hline AGR (high/low) & $<0.001$ & $0.323(0.191-0.547)$ & $0.00 \mathrm{I}^{\mathrm{a}}$ & $0.402(0.233-0.691)$ \\
\hline Albumin $\geq 37.65 \mathrm{~g} / \mathrm{L}$ & 0.002 & $0.500(0.323-0.775)$ & $0.009^{a}$ & $0.546(0.347-0.857)$ \\
\hline Globulin $>32 \mathrm{~g} / \mathrm{L}$ & 0.020 & $1.688(1.085-2.628)$ & $0.105^{\mathrm{a}}$ & $1.450(0.925-2.272)$ \\
\hline
\end{tabular}

Notes: aAdjusting covariates including AFP, HBV infection, cancer embolus, and TNM stages. To avoid collinearity bias BCLC score and tumor, entered into the multivariate model but tested independently. Bold font represents $P<0.05$ and the relevant variables are statistically significant.

Abbreviations: HCC, hepatocellular carcinoma; HR, hazard ratio; AFP, alpha-fetoprotein; HBV, hepatitis B virus; HCV, hepatitis C virus; TNM, tumor node metastasis; BCLC, Barcelona clinical liver cancer; AGR, albumin/globulin ratio; Cl, confidence interval; CTP, Child-Turcotte-Pugh. 
Table 4 Univariate and multivariate analysis of factors associated with HCC recurrence

\begin{tabular}{|c|c|c|c|c|}
\hline \multirow[t]{2}{*}{ Parameters } & \multicolumn{2}{|c|}{ Univariate analysis } & \multicolumn{2}{|c|}{ Multivariate analysis } \\
\hline & $P$-value & HR $(95 \% \mathrm{Cl})$ & $P$-value & HR $(95 \% \mathrm{Cl})$ \\
\hline Age $>60$ years & 0.557 & I.I57 (0.7I2-I.880) & & \\
\hline Sex (male/female) & 0.757 & $0.917(0.527-1.593)$ & & \\
\hline Smoking (yes/no) & 0.551 & $0.866(0.540-1.389)$ & & \\
\hline Drinking (yes/no) & 0.610 & $0.866(0.498-1.505)$ & & \\
\hline AFP $\geq 400 \mathrm{ng} / \mathrm{mL}$ & 0.005 & $2.057(1.250-3.386)$ & 0.039 & $\mathrm{I} .708(\mathrm{I} .027-2.838)$ \\
\hline Platelet $<100\left(10^{9} / \mathrm{L}\right)$ & 0.148 & $0.689(0.4 I 6-1.14 I)$ & & \\
\hline CTP Class (A/B) & 0.086 & $1.981(0.908-4.322)$ & & \\
\hline HBV infection (yes/no) & 0.134 & $1.444(0.893-2.334)$ & & \\
\hline HCV infection (yes/no) & 0.428 & $0.567(0.139-2.311)$ & & \\
\hline Cancer embolus (yes/no) & 0.024 & $2.237(1.113-4.495)$ & 0.857 & $\mathrm{I} .074(0.495-2.332)$ \\
\hline Tumor size $(<5 / \geq 5)(\mathrm{cm})$ & $<\mathbf{0 . 0 0 I}$ & $4.95 I(2.604-9.415)$ & & \\
\hline Tumor number $(I />I)$ & 0.133 & $\mathrm{I} .50 \mathrm{I}(0.883-2.55 \mathrm{I})$ & & \\
\hline TNM stages (per increase I stage) & 0.001 & 1.575 ( $1.199-2.068)$ & 0.015 & $1.464(1.078-1.989)$ \\
\hline BCLC stage (per increase I stage) & $<\mathbf{0 . 0 0 I}$ & $1.76 \mathrm{I}(\mathrm{I} .32 \mathrm{I}-2.347)$ & & \\
\hline Liver cirrhosis (yes/no) & 0.285 & $0.765(0.468-1.25 I)$ & & \\
\hline AGR (high/low) & 0.001 & $0.418(0.252-0.694)$ & $0.008^{a}$ & $0.493(0.293-0.828)$ \\
\hline Albumin $\geq 37.65 \mathrm{~g} / \mathrm{L}$ & 0.033 & $0.609(0.386-0.960)$ & $0.105^{\mathrm{a}}$ & $0.678(0.425-1.084)$ \\
\hline Globulin $>32 \mathrm{~g} / \mathrm{L}$ & 0.020 & $1.729(1.09 I-2.74 I)$ & $0.066^{a}$ & I.545 (0.97|-2.458) \\
\hline
\end{tabular}

Notes: aAdjusting covariates including AFP, cancer embolus, and TNM stages. To avoid collinearity bias BCLC score and tumor size were not entered into the multivariate model but tested independently. Bold font represents $P<0.05$ and the relevant variables are statistically significant.

Abbreviations: HCC, hepatocellular carcinoma; HR, hazard ratio; AFP, alpha-fetoprotein; HBV, hepatitis B virus; HCV, hepatitis C virus; TNM, tumor node metastasis; BCLC, Barcelona clinical liver cancer; AGR, albumin/globulin ratio; Cl, confidence interval; CTP, Child-Turcotte-Pugh.

at TNM II $(P=0.043)$ and TNM III $(P=0.003)$. Besides, a low AGR value might significantly increase recurrence probability in patients with TNM III $(P=0.005)$.

Previous reports suggested that hypoalbuminemia could function as an independent risk factor of predicting prognosis in malignancies. With the purpose of excluding the effect of hypoalbuminemia, Kaplan-Meier survival analysis was done among those patients who had albumin $>35 \mathrm{~g} / \mathrm{L}$. Whether predicting OS $(P=0.002)$ or recurrence $(P=0.004)$, AGR remained a significant predictor (Figure 5).

Surgical treatment might largely account for early death or recurrence. Hence, additional analysis was further conducted among those patients who survived beyond 6 months to determine if the association between AGR and prognosis was merely secondary to the short-term mortality. Interestingly, AGR showed superior ability to predict OS and recurrence compared with albumin or globulin alone (Figure 6).

\section{Stratification of patients according to AGR and tumor size}

Low AGR is the significant reflection of liver functional impairment of patients with $\mathrm{HCC}$, while tumor size could well take into account the anatomical characteristics of liver tumor. As shown in Table 5, the combination of AGR and
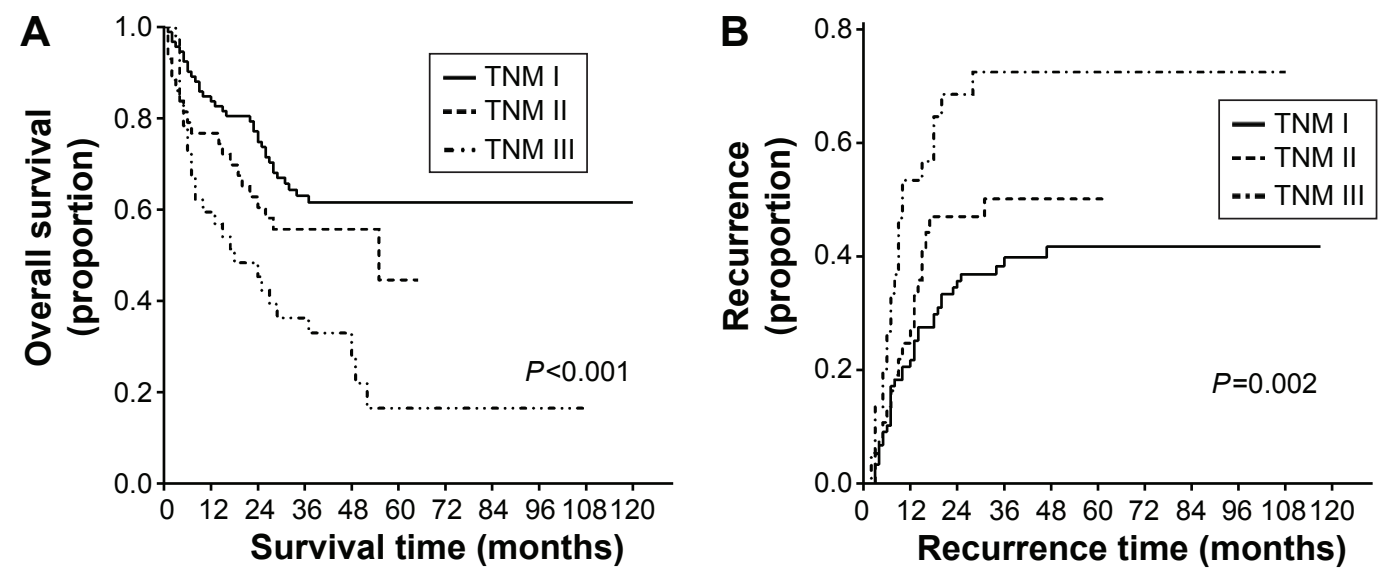

Figure 3 Kaplan-Meier curves for (A) OS and (B) recurrence among different TNM stages.

Note: The $P$-values were calculated by log-rank test.

Abbreviations: TNM, tumor node metastasis; OS, overall survival. 

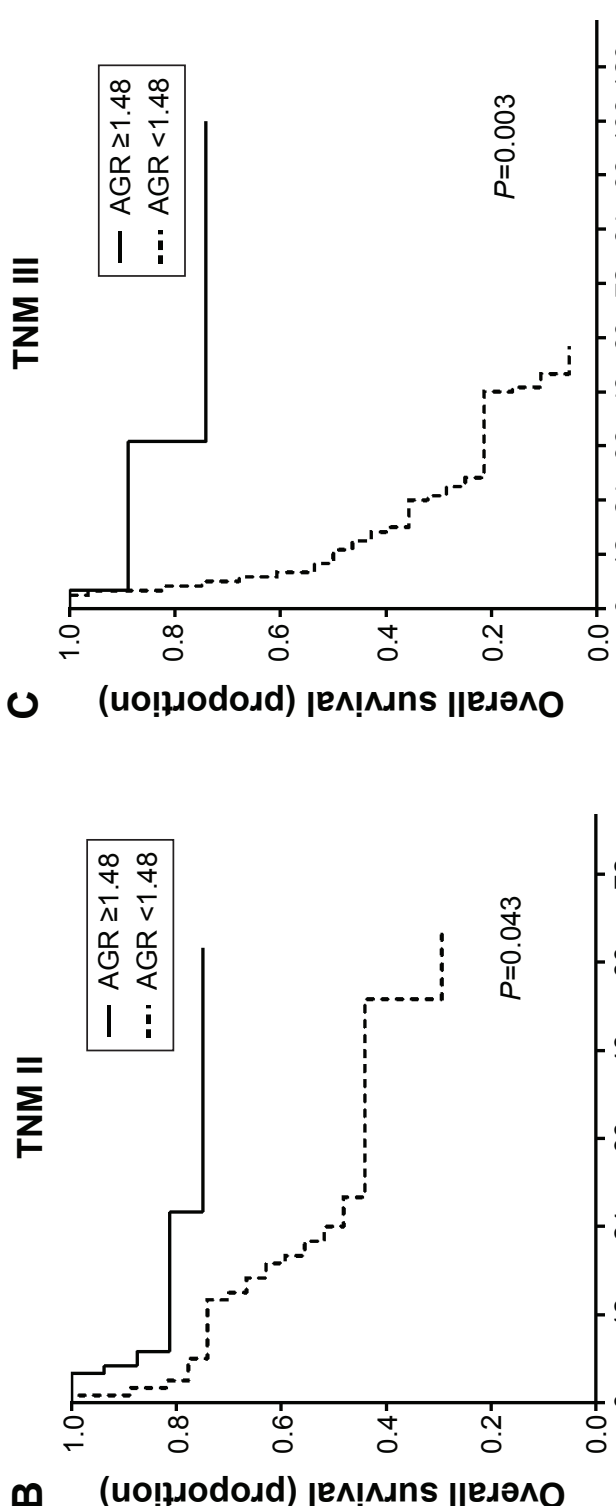

m (uo!juodosd) jeл!̣ıns ןеләло

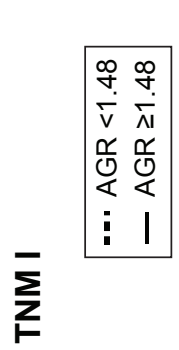

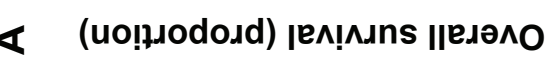

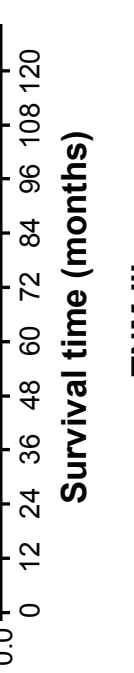

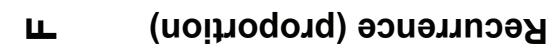

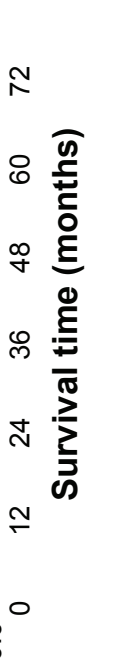

ш
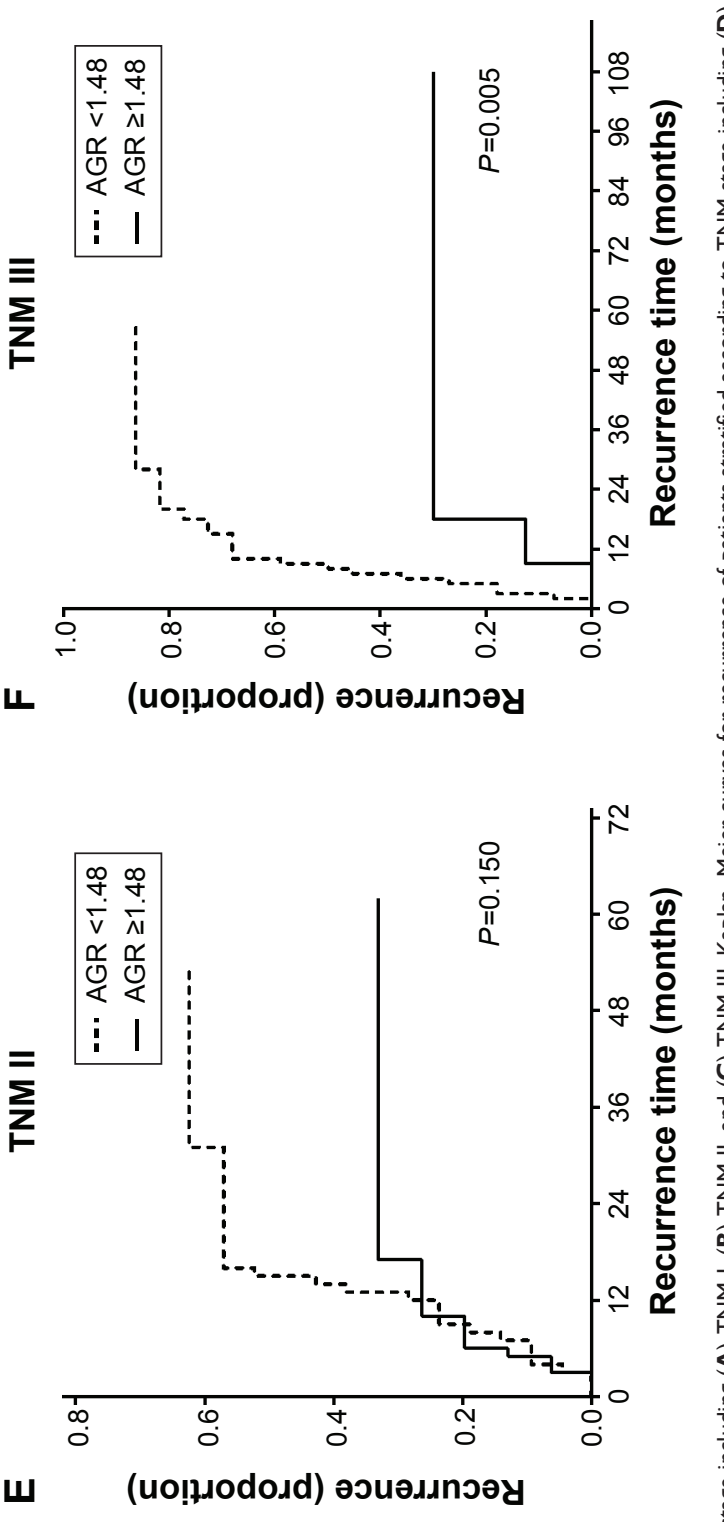

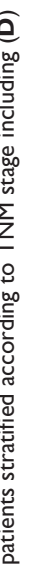

$$
\text { (a) }
$$



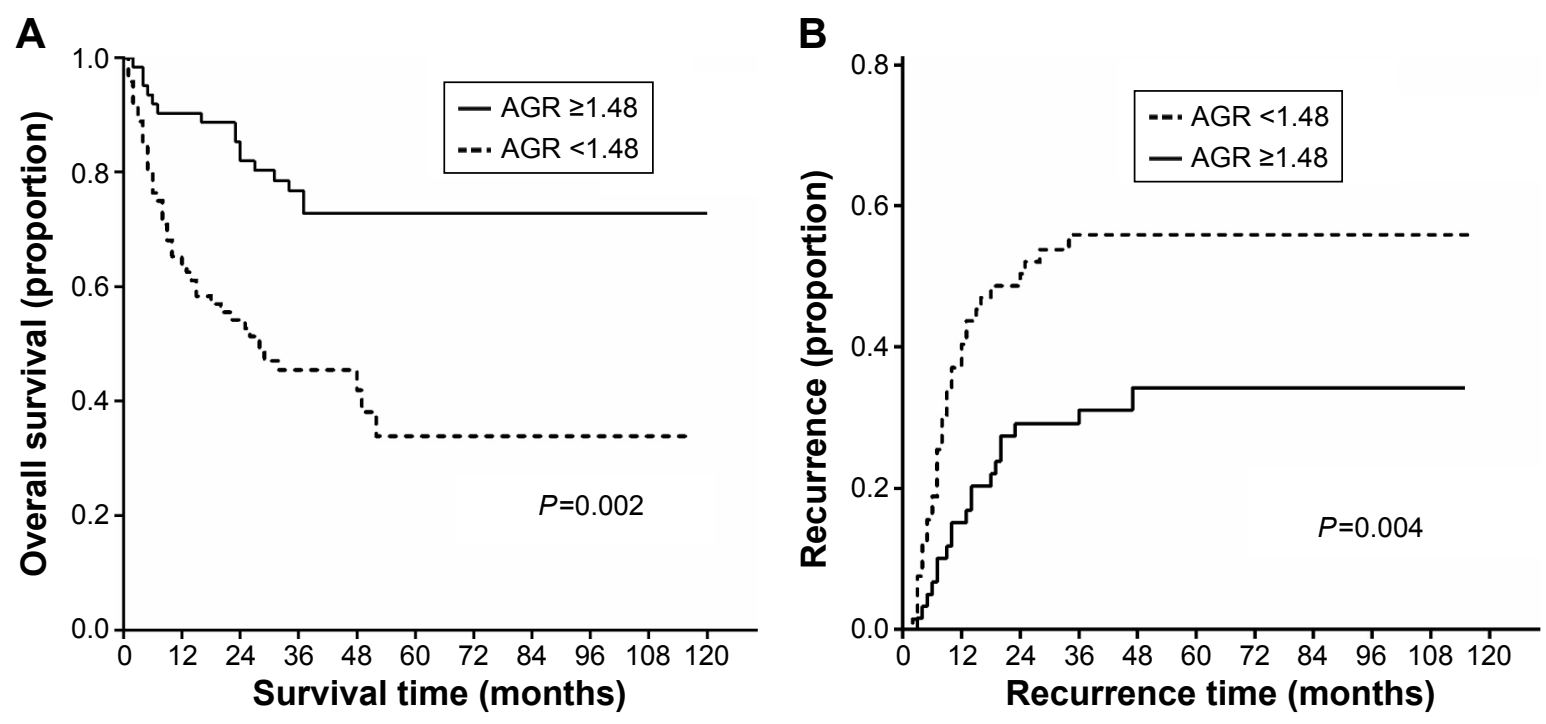

Figure 5 Kaplan-Meier curves for OS (A) and recurrence (B) between high-AGR (AGR $\geq 1.48$ ) and low-AGR (AGR $<$ I.48) among patients with normal albumin. Note: The $P$-values were calculated by log-rank test.

Abbreviations: OS, overall survival; AGR, albumin/globulin ratio.

tumor size discovered a higher diagnostic accuracy in predicting postoperative clinical outcome of patients with $\mathrm{HCC}$ after surgery than BCLC stage score (concordance index: $0.769,95 \%$ CI: $0.698-0.840$ vs $0.712,95 \%$ CI: $0.619-0.805$ ). Therefore, all the patients were divided into three groups, namely Group A (AGR $\geq 1.48$ and tumor size $<5 \mathrm{~cm}$, $\mathrm{n}=28$ ), Group $\mathrm{B}$ ( $\mathrm{AGR} \geq 1.48$ but tumor size $\geq 5 \mathrm{~cm}$, or tumor size $<5 \mathrm{~cm}$ but AGR $<1.48, \mathrm{n}=69$ ), and Group C (AGR $<1.48$ and tumor size $\geq 5 \mathrm{~cm}, \mathrm{n}=75$ ). The patients in Group A had a significantly better clinical outcome compared with patients in Group B or C $(P<0.001$; Figure 7).

\section{Discussion}

A group of patients with HCC suffering from radical hepatic carcinectomy still had high mortality and recurrence rate; consequently, factors associated with reduced OS or increased

\section{A}

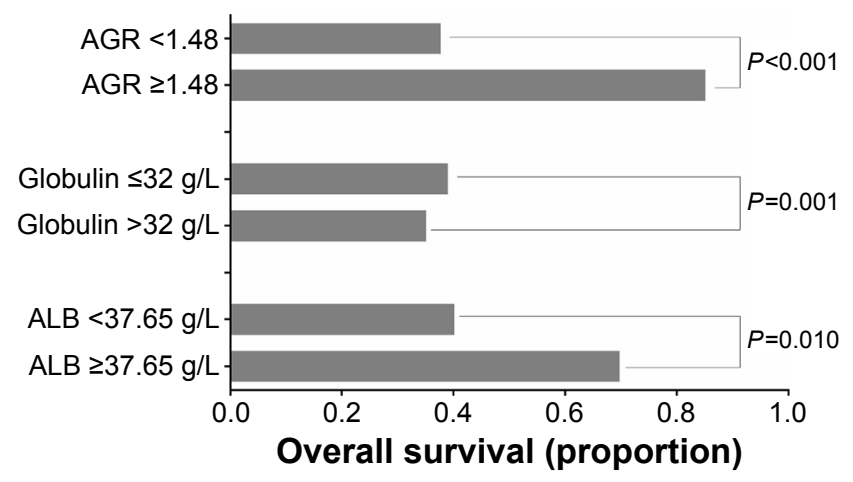

recurrence should provide the ability to preselect those patients who would benefit most from more aggressive treatments. ${ }^{14}$ Several studies stated that serum AFP, traditional tumorrelated factors, and a number of molecular or gene biomarkers might function as independent parameters in predicting outcome. Nevertheless, it was becoming increasingly apparent that those factors had numerous limitations and deficiencies. The first and foremost, preoperative and postoperative levels of serum AFP have a negative detection rate of $>20 \%-80 \% .^{15}$ In addition, the prognostic value of tumor-related factors such as the TNM staging system is inadequate just in terms of disease progression. ${ }^{16}$ Besides, those molecular or gene biomarkers have an obvious heterogeneity in predicting prognosis. ${ }^{17}$ The last but not the least, a slice of examinations are invasive or dispensable before operation, thus the clinical and practical value is largely limited. Therefore, the identification of

B

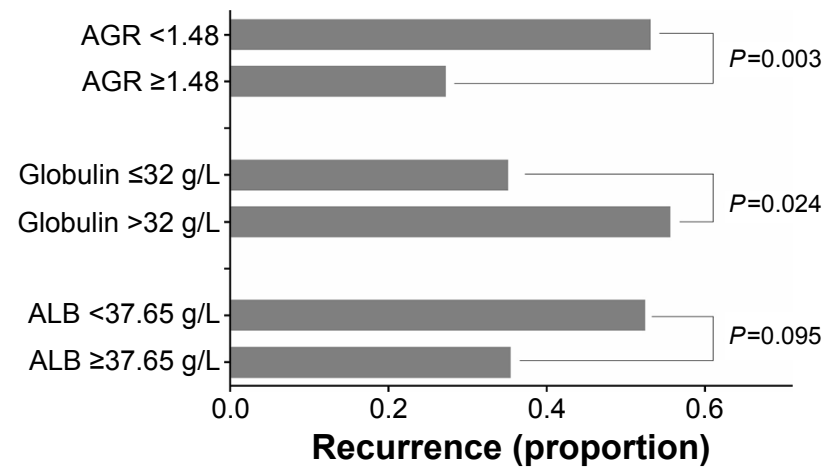

Figure 6 Histograms compare the 5 -year mortality $(\mathbf{A})$ and recurrence rate (B) between high-AGR and low-AGR groups of ALB, GLB, and AGR based on the optimal cutoff values.

Note: The $P$-values were calculated by log-rank test.

Abbreviations: ALB, albumin; GLB, globulin; AGR, albumin/globulin ratio. 
Table 5 Ranking of discriminatory ability of the prognostic systems on the basis of C-index

\begin{tabular}{llll}
\hline Rank & Systems & C-index & $\mathbf{9 5 \%} \mathbf{C l}$ \\
\hline I & AGR + tumor size & 0.769 & $0.698-0.840$ \\
2 & BCLC & 0.712 & $0.619-0.805$ \\
3 & AGR & 0.658 & $0.576-0.740$ \\
\hline
\end{tabular}

Note: C-index reflects the ability to predict survival: the greater the C-index, the more accurate the prognostic prediction.

Abbreviations: C-index, concordance index; AGR, albumin/globulin ratio; BCLC, Barcelona clinical liver cancer; $\mathrm{Cl}$, confidence interval.

a simple, objective, and useful index to predict malignant patients' prognosis is of vital importance.

Nowadays, chronic inflammation is a critical contributor to tumor development, proliferation, and metastasis and is also related to the risk of death and recurrence among malignant patients after surgery. ${ }^{18}$ The inflammation-based prognostic score such as Glasgow prognostic score, ${ }^{19}$ neutrophil-to-lymphocyte ratio, ${ }^{20}$ aspartate aminotransferaseto-platelet ratio, ${ }^{21}$ and platelet-to-lymphocyte ratio ${ }^{22}$ was proven to be independent prognostic parameters by previous studies. However, there are still some limitations for the use of these prognostic scores in patients with HCC. First, the effects of preoperative platelets level on the clinical outcomes of HCC remain contradictory and controversial. On the one hand, platelets contribute to liver regeneration and preoperative low platelets were associated with a high risk of death in patients with $\mathrm{HCC}^{23}$ On the other hand, high level of pretreatment platelets was verified as a significant predictive factor of an elevated risk of extrahepatic metastasis among patients with HCC. ${ }^{24}$ Therefore, relevant models, including aminotransferase-to-platelet ratio and platelet-to-lymphocyte ratio, have some limitations to predict survival in HCC. Second, unlike other cancers, clinical outcome in patients with $\mathrm{HCC}$ is prone to be influenced by the underlying liver function along with the extent of spread of primary tumor. ${ }^{25}$ In the context of HCC, the neutrophil-to-lymphocyte ratio, just derived from circulating differential white blood cell count, might insufficiently reflect the liver function. Albumin, completely produced by liver, could commendably reveal the liver functions of patients with $\mathrm{HCC}$, and globulin is composed of all kinds of proinflammatory proteins including acute-phase protein (CRP). Hence, we believe that AGR is superior to Glasgow prognostic score, which is calculated based on CRP and serum albumin, as a prognostic biomarker of systemic inflammation.

Serum albumin, produced by liver, maintains osmotic pressure and functions as a carrier to transport various kinds of metabolic substances. Increasing evidence showed that hypoalbuminemia indicated persons' malnutrition, which was associated with poor OS and high recurrence in patients with gastric, colorectal, pancreatic, lung, ovarian, breast, and liver cancer. ${ }^{8,26,27}$ Even though the mechanism by which low albumin may impact on OS or recurrence is not completely discovered, there are several reasons to explain it. Albumin is an antioxidant, which has the ability to buffer some biochemical changes, stabilize cell growth and DNA replication, and maintain sex hormone homeostasis. ${ }^{28}$ In addition, high level of serum albumin could function as antiproliferative reagent in human cancer cells in vitro. ${ }^{29,30}$ Besides, hypoalbuminemia is not only a syndrome of poor nutritional status but also associated with chronic inflammation. ${ }^{31,32}$ Low serum albumin could weaken human defense system, thus
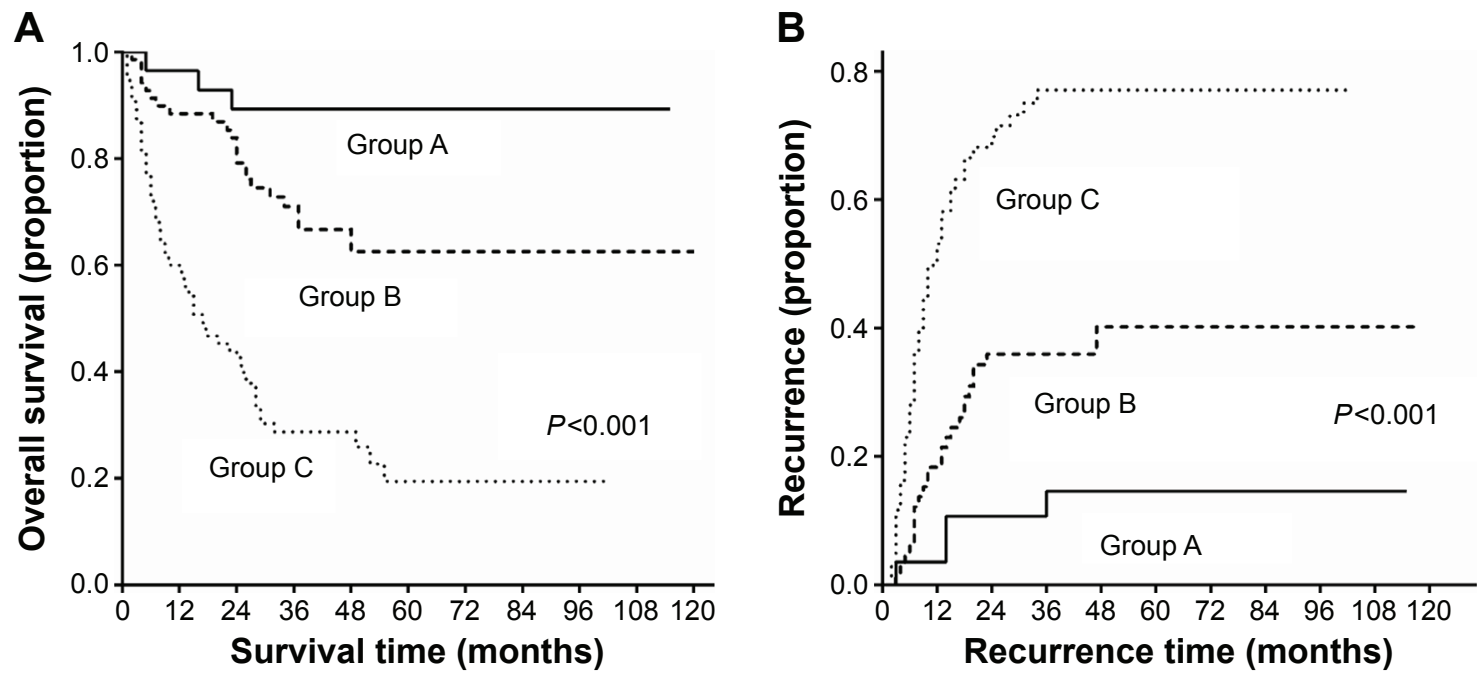

Figure 7 Kaplan-Meier curves for OS (A) and recurrence $(B)$ of the subgroup study stratification of patients according to AGR and tumor size.

Notes: Group A (AGR $\geq 1.48$ and tumor size $<5 \mathrm{~cm}, \mathrm{n}=28$ ). Group $B(A G R \geq 1.48$ but tumor size $\geq 5 \mathrm{~cm}$, or tumor size $<5 \mathrm{~cm}$ but $A G R<1.48$, $n=69$ ), and $G$ roup $C$ (AGR $<1.48$ and tumor size $\geq 5 \mathrm{~cm}, \mathrm{n}=75$ ). The $P$-values were calculated by log-rank test.

Abbreviations: OS, overall survival; AGR, albumin/globulin ratio. 
increasing susceptibility to infect and resulting in cytokineinduced suppression, which affect long-term OS and recurrence. ${ }^{33,34}$ Prognostic value of albumin was also proven among those HCC patients following the surgical treatment in current investigation.

Globulin (total protein - albumin) consists of all kinds of proinflammatory proteins. High level of globulin indicated a systematic inflammatory response. ${ }^{14}$ With the development of tumor biology, growing evidence suggested that a systematic inflammatory response played an indispensable role in proliferation, progression, development, and metastasis of tumor cells by altering its biological features and destroying host immune function. ${ }^{35}$ Convincing evidence supported the concept that inflammatory pathways can be redirected into a tumor-promoting path by the peritumoral stroma through the activation of innate immunity in HCC. ${ }^{36-38}$ In addition, patients with malignancy might largely benefit from taking regular nonsteroidal anti-inflammatory drugs such as aspirin. ${ }^{39,40}$ Additionally, HBV infection is closely related to $\mathrm{HCC}$ occurring in the East and mediate the consistent expression of HBV immunogenic proteins, resulting in a potent systematic inflammatory. ${ }^{2}$ Similar to previous results in our study, we observed that the patients with HBV infection had significantly worse OS compared with counterparts with no HBV infection. Finally, chronic oxidative stress and oxygen-free radicals from a systematic inflammatory response had been manifested to stimulate tumor initiation, promotion, and progression. ${ }^{41}$

Systematic inflammatory responses could inhibit synthetic function of liver leading to hypoabluminemia. ${ }^{3,10}$ When it comes to malignancy, malnutrition and systematic inflammatory are inseparable in predicting the oncological outcome. AGR, a combination of the two earlier mentioned predictors, reflects nutrition and systemic inflammatory states at the same time. Our study, consistent with previous reports, ${ }^{11,14,42-46}$ concluded that patients with high-AGR had better OS and lower recurrence rate compared with those with low-AGR, especially in normal serum albumin and the cohort whose survival time was beyond 6 months. Furthermore, there was no difficulty to find that AGR was a superior predictive index compared with albumin or globulin alone. Besides, AGR is less sensitive and susceptible to measurement variability such as dehydration or fluid retention, as it is a ratio instead of absolute value alone. ${ }^{11}$ Nowadays, several prognostic stage models, including BCLC, ${ }^{47}$ the Japan Integrated Staging, ${ }^{48}$ Cancer of the Liver Italian Program, ${ }^{49}$ and Chinese University Prognostic Index, ${ }^{50}$ are subsequently used to stratify HCC. Among the earlier mentioned models, the BCLC stage has been proven to be an independent prognostic biomarker by numerous investigations and has been used in the clinical setting worldwide. ${ }^{51}$ In our study, the combination of AGR and tumor size showed a higher diagnostic accuracy in predicting postoperative OS compared with BCLC stage.

In the course of our investigation, AGR was also found to correlate significantly with age and the presence of cancer embolus. Elderly patients tend to develop poor immunological status and malnutrition due to physical function and appetite loss. ${ }^{52,53}$ Hence, AGR does tend to be lower in elderly patients than the other patients. Although it has been suggested that patients with liver cirrhosis tend to have poor outcomes, the relationship was not seen in this study. ${ }^{54,55}$ This may be due to various postoperative factors that were not identified in the study and exceed the impact of liver cirrhosis in terms of the effect on the prognosis.

As far as we know, our study is the first to demonstrate the relation between ARG and outcome of patients following the surgical treatment of HCC. Nevertheless, there are some limitations or weaknesses in our study, inevitably. To begin with, the study is a retrospective analysis, some preoperative medical cases or follow-up data were incomplete, which may lead to a negative impact on the survival outcome. Besides, as CRP, an important indicator of cancer-related inflammation, was not routinely measured in the past, the correlation between CRP and AGR was not analyzed. Therefore, the function of AGR still needs to be confirmed via multicenter clinical study.

Despite these limitations, pretreatment AGR is an independent predictor of long-term mortality and recurrence. As a result, this biomarker, characterized with easy accessibility, objectivity, and noninvasiveness, might provide the ability to preselect patients who would benefit most from more aggressive treatments in the clinical setting.

\section{Acknowledgments}

The study was supported by the Clinical Research Award of the First Affiliated Hospital of Xi' an Jiaotong University, People's Republic of China (No XJTU1AF-CRF-2015-003).

\section{Disclosure}

The authors report no conflicts of interest in this work.

\section{References}

1. Younossi ZM, Otgonsuren M, Henry L, et al. Association of nonalcoholic fatty liver disease (NAFLD) with hepatocellular carcinoma (HCC) in the United States from 2004 to 2009. Hepatology. 2015;62(6): $1723-1730$. 
2. Kabbach G, Assi HA, Bolotin G, Schuster M, Lee HJ, Tadros M. Hepatobiliary tumors: update on diagnosis and management. $J$ Clin Transl Hepatol. 2015;3(3):169-181.

3. Pinato DJ, North BV, Sharma R. A novel, externally validated inflammation-based prognostic algorithm in hepatocellular carcinoma: the prognostic nutritional index (PNI). Br J Cancer. 2012;106(8): 1439-1445.

4. Wang $\mathrm{C}$, Wang $\mathrm{H}$, Yang $\mathrm{W}$, et al. Multicenter randomized controlled trial of percutaneous cryoablation versus radiofrequency ablation in hepatocellular carcinoma. Hepatology. 2015;61(5): 1579-1590.

5. Tsurusaki M, Murakami T. Surgical and locoregional therapy of HCC: TACE. Liver Cancer. 2015;4(3):165-175.

6. Chu-Yuan H, Jing P, Yi-Sheng W, et al. The impact of chemotherapy-associated neutrophil/lymphocyte counts on prognosis of adjuvant chemotherapy in colorectal cancer. BMC Cancer. 2013; 13:177.

7. Chen KL, Liu YH, Li WY, et al. The prognostic nutritional index predicts survival for patients with extranodal natural killer/T cell lymphoma, nasal type. Ann Hematol. 2015;94(8):1389-1400.

8. Fox P, Hudson M, Brown C, et al. Markers of systemic inflammation predict survival in patients with advanced renal cell cancer. Br J Cancer. 2013;109(1):147-153.

9. Park JH, Watt DG, Roxburgh CS, Horgan PG, McMillan DC. Colorectal cancer, systemic inflammation, and outcome: staging the tumor and staging the host. Ann Surg. 2016;263(2):326-336.

10. Gupta D, Lis CG. Pretreatment serum albumin as a predictor of cancer survival: a systematic review of the epidemiological literature. Nutr J. 2010;9:69.

11. Azab B, Kedia S, Shah N, et al. The value of the pretreatment albumin/ globulin ratio in predicting the long-term survival in colorectal cancer. Int J Colorectal Dis. 2013;28(12):1629-1636.

12. Chen J, Zhou Y, Xu Y, Zhu HY, Shi YQ. Low pretreatment serum globulin may predict favorable prognosis for gastric cancer patients. Tumour Biol. 2016;37(3):3905-3911.

13. Edge SB, Compton CC. The American Joint Committee on Cancer: the 7th edition of the AJCC cancer staging manual and the future of TNM. Ann Surg Oncol. 2010;17(6):1471-1474.

14. Du XJ, Tang LL, Mao YP, et al. The pretreatment albumin to globulin ratio has predictive value for long-term mortality in nasopharyngeal carcinoma. PLoS One. 2014;9(4):e94473.

15. Sherman M. The resurrection of alphafetoprotein. J Hepatol. 2010; 52(6):939-940.

16. Sherman M. Hepatocellular carcinoma: screening and staging. Clin Liver Dis. 2011;15(2):323-334, vii-x.

17. Marusyk A, Polyak K. Tumor heterogeneity: causes and consequences. Biochim Biophys Acta. 2010;1805(1):105-117.

18. Coussens LM, Werb Z. Inflammation and cancer. Nature. 2002; 420(6917):860-867.

19. Ferro M, De Cobelli O, Buonerba C, et al. Modified glasgow prognostic score is associated with risk of recurrence in bladder cancer patients after radical cystectomy: a multicenter experience. Medicine (Baltimore). 2015;94(42):e1861.

20. Marchioni M, Primiceri G, Ingrosso M, et al. The clinical use of the neutrophil to lymphocyte ratio (NLR) in urothelial cancer: a systematic review. Clin Genitourin Cancer. Epub 2016 Apr 22.

21. Leung DH, Khan M, Minard CG, et al. Aspartate aminotransferase to platelet ratio and fibrosis- 4 as biomarkers in biopsy-validated pediatric cystic fibrosis liver disease. Hepatology. 2015;62(5):1576-1583.

22. You J, Zhu GQ, Xie L, et al. Preoperative platelet to lymphocyte ratio is a valuable prognostic biomarker in patients with colorectal cancer Oncotarget. Epub 2016 Mar 24.

23. Pang Q, Qu K, Zhang JY, et al. The prognostic value of platelet count in patients with hepatocellular carcinoma: a systematic review and meta-analysis. Medicine (Baltimore). 2015;94(37):e1431.

24. Lee $\mathrm{CH}$, Lin YJ, Lin CC, et al. Pretreatment platelet count early predicts extrahepatic metastasis of human hepatoma. Liver Int. 2015; 35(10):2327-2336.
25. Bruix J, Sherman M, Llovet JM, et al. Clinical management of hepatocellular carcinoma. Conclusions of the Barcelona-2000 EASL conference. European Association for the Study of the Liver. J Hepatol. 2001; 35(3):421-430.

26. Wu N, Chen G, Hu H, Pang L, Chen Z. Low pretherapeutic serum albumin as a risk factor for poor outcome in esophageal squamous cell carcinomas. Nutr Cancer. 2015;67(3):481-485.

27. Yamashita K, Ushiku H, Katada N, et al. Reduced preoperative serum albumin and absence of peritoneal dissemination may be predictive factors for long-term survival with advanced gastric cancer with positive cytology test. Eur J Surg Oncol. 2015;41(10): 1324-1332.

28. Seaton K. Albumin concentration controls cancer. J Natl Med Assoc. 2001;93(12):490-493.

29. Laursen I, Briand P, Lykkesfeldt AE. Serum albumin as a modulator on growth of the human breast cancer cell line, MCF-7. Anticancer Res. 1990;10(2A):343-351.

30. Sonnenschein C, Soto AM, Michaelson CL. Human serum albumin shares the properties of estrocolyone-I, the inhibitor of the proliferation of estrogen-target cells. J Steroid Biochem Mol Biol. 1996;59(2): $147-154$.

31. Kaysen GA. The microinflammatory state in uremia: causes and potential consequences. J Am Soc Nephrol. 2001;12(7):1549-1557.

32. McMillan DC, Watson WS, O'Gorman P, Preston T, Scott HR, McArdle CS. Albumin concentrations are primarily determined by the body cell mass and the systemic inflammatory response in cancer patients with weight loss. Nutr Cancer. 2001;39(2):210-213.

33. Fearon KC, Falconer JS, Slater C, McMillan DC, Ross JA, Preston T. Albumin synthesis rates are not decreased in hypoalbuminemic cachectic cancer patients with an ongoing acute-phase protein response. Ann Surg. 1998;227(2):249-254.

34. Stehle G, Wunder A, Hartung G, Sinn H. Albumin synthesis rates in cachectic cancer patients with an ongoing acute-phase protein response. Ann Surg. 1998;228(5):720.

35. Vawda S, Mansour R, Takeda A, et al. Associations between inflammatory and immune response genes and adverse respiratory outcomes following exposure to outdoor air pollution: a HuGE systematic review. Am J Epidemiol. 2014;179(4):432-442.

36. Kuang DM, Zhao Q, Wu Y, et al. Peritumoral neutrophils link inflammatory response to disease progression by fostering angiogenesis in hepatocellular carcinoma. J Hepatol. 2011;54(5):948-955.

37. Ahmad J, Grimes N, Farid S, Morris-Stiff G. Inflammatory response related scoring systems in assessing the prognosis of patients with pancreatic ductal adenocarcinoma: a systematic review. Hepatobiliary Pancreat Dis Int. 2014;13(5):474-481.

38. van Dijk RA, Duinisveld AJ, Schaapherder AF, et al. A change in inflammatory footprint precedes plaque instability: a systematic evaluation of cellular aspects of the adaptive immune response in human atherosclerosis. J Am Heart Assoc. 2015;4(4):ii:e001403.

39. Burn J, Gerdes A-M, Macrae F, et al. Long-term effect of aspirin on cancer risk in carriers of hereditary colorectal cancer: an analysis from the CAPP2 randomised controlled trial. Lancet. 2011;378(9809): 2081-2087.

40. Liao D, Zhong L, Duan T, et al. Aspirin suppresses the growth and metastasis of osteosarcoma through the NF-kappaB pathway. Clin Cancer Res. 2015;21(23):5349-5359.

41. Szkandera J, Pichler M, Absenger G, et al. The elevated preoperative platelet to lymphocyte ratio predicts decreased time to recurrence in colon cancer patients. Am J Surg. 2014;208(2):210-214.

42. Azab BN, Bhatt VR, Vonfrolio S, et al. Value of the pretreatment albumin to globulin ratio in predicting long-term mortality in breast cancer patients. Am J Surg. 2013;206(5):764-770.

43. Duran AO, Inanc M, Karaca H, et al. Albumin-globulin ratio for prediction of long-term mortality in lung adenocarcinoma patients. Asian Pac J Cancer Prev. 2014;15(15):6449-6453.

44. Shibutani M, Maeda K, Nagahara H, et al. The pretreatment albumin to globulin ratio predicts chemotherapeutic outcomes in patients with unresectable metastatic colorectal cancer. BMC Cancer. 2015;15:347. 
45. Suh B, Park S, Shin DW, et al. Low albumin-to-globulin ratio associated with cancer incidence and mortality in generally healthy adults. Ann Oncol. 2014;25(11):2260-2266.

46. Zhang B, Yu W, Zhou LQ, et al. Prognostic significance of preoperative albumin-globulin ratio in patients with upper tract urothelial carcinoma. PLoS One. 2015;10(12):e0144961.

47. Llovet JM, Bru C, Bruix J. Prognosis of hepatocellular carcinoma: the BCLC staging classification. Semin Liver Dis. 1999;19(3):329-338.

48. Kubo S, Tanaka H, Shuto T, et al. Prognostic effects of causative virus in hepatocellular carcinoma according to the Japan integrated staging (JIS) score. J Gastroenterol. 2005;40(10):972-979.

49. Ueno S, Tanabe G, Sako K, et al. Discrimination value of the new western prognostic system (CLIP score) for hepatocellular carcinoma in 662 Japanese patients. Cancer of the Liver Italian Program. Hepatology. 2001;34(3):529-534.

50. Leung TW, Tang AM, Zee B, et al. Construction of the Chinese University Prognostic Index for hepatocellular carcinoma and comparison with the TNM staging system, the Okuda staging system, and the Cancer of the Liver Italian Program staging system: a study based on 926 patients. Cancer. 2002;94(6):1760-1769.
51. Adhoute X, Penaranda G, Bronowicki JP, Raoul JL. Usefulness of the HKLC vs. the BCLC staging system in a European HCC cohort. J Hepatol. 2015;62(2):492-493.

52. Gao Y, Zhou S, Jiang W, Huang M, Dai X. Effects of ganopoly (a Ganoderma lucidum polysaccharide extract) on the immune functions in advanced-stage cancer patients. Immunol Invest. 2003; 32(3):201-215.

53. Suzana S, Boon PC, Chan PP, Normah CD. Malnutrition risk and its association with appetite, functional and psychosocial status among elderly Malays in an agricultural settlement. Malays J Nutr. 2013; 19(1):65-75.

54. Nau C, Wutzler S, Dorr H, et al; Trauma Registry of DGU. Liver cirrhosis but not alcohol abuse is associated with impaired outcome in trauma patients - a retrospective, multicentre study. Injury. 2013;44(5): 661-666.

55. Refky B, Kotb S, Fady T, et al. Impact of liver cirrhosis due to chronic hepatitis $\mathrm{C}$ viral infection on the outcome of ovarian cancer: a prospective study. BMC Cancer. 2015;15:754.
OncoTargets and Therapy

\section{Publish your work in this journal}

OncoTargets and Therapy is an international, peer-reviewed, open access journal focusing on the pathological basis of all cancers, potential targets for therapy and treatment protocols employed to improve the management of cancer patients. The journal also focuses on the impact of management programs and new therapeutic agents and protocols on

\section{Dovepress}

patient perspectives such as quality of life, adherence and satisfaction The manuscript management system is completely online and includes a very quick and fair peer-review system, which is all easy to use. Visit http://www.dovepress.com/testimonials.php to read real quotes from published authors. 